\title{
Patients' preferences for osteoporosis drug treatment: a discrete-choice experiment
}

\author{
Mickaël Hiligsmann ${ }^{1 *}$, Benedict G Dellaert ${ }^{2}$, Carmen D Dirksen ${ }^{3}$, Trudy van der Weijden ${ }^{4}$, Stefan Goemaere ${ }^{5}$, \\ Jean-Yves Reginster ${ }^{6}$, Verity Watson ${ }^{7}$ and Annelies Boonen ${ }^{8}$
}

\begin{abstract}
Introduction: The patient's perspective is becoming increasingly important in clinical and policy decisions. In this study, we aimed to evaluate the preferences of patients with, or at risk of, osteoporosis for medication attributes, and to establish how patients trade between these attributes.

Methods: A discrete choice experiment survey was designed and patients were asked to choose between two hypothetical unlabelled drug treatments (and an opt-out option) that vary in five attributes: efficacy in reducing the risk of fracture, type of potential common side-effects, mode and frequency of administration and out-of-pocket costs. An efficient experimental design was used to construct the treatment option choice sets and a mixed logit panel data model was used to estimate patients' preferences and trade-offs between attributes.

Results: A total of 257 patients with, or at risk of, osteoporosis completed the experiment. As expected, patients preferred treatment with higher effectiveness and lower cost. They also preferred either an oral monthly tablet or 6-month subcutaneous injection above weekly oral tablets, 3-month subcutaneous, 3-month intravenous or yearly intravenous injections. Patients disliked being at risk of gastro-intestinal disorders more than being at risk of skin reactions and flu-like symptoms. There was significant variation in preferences across the sample for all attributes except subcutaneous injection.
\end{abstract}

Conclusions: This study revealed that osteoporotic patients preferred 6-month subcutaneous injection and oral monthly tablet, and disliked gastro-intestinal disorders. Moreover, patients were willing to pay a personal contribution or to trade treatment efficacy for better levels of other attributes. Preferences for treatment attributes varied across patients and this highlights the importance of clinical decision-making taking individual preferences into account to improve osteoporosis care.

\section{Introduction}

The patient's perspective is becoming increasingly important in clinical and policy decisions. Information about what patients need and prefer, and how they value various aspects of a health intervention can be useful when designing and evaluating healthcare programs [1]. A better understanding of patients' preferences for treatment can help health professionals to improve disease management. When differences in efficacy or safety do not determine the choice of a specific treatment, patient's satisfaction with therapy is important [2].

\footnotetext{
* Correspondence: m.hiligsmann@maastrichtuniversity.nl

'Department of Health Services Research, School for Public Health and Primary Care (CAPHRI), Maastricht University, P.O. Box 616, 6200 MD

Maastricht, the Netherlands

Full list of author information is available at the end of the article
}

Addressing patients' concerns with treatment and involving them in clinical decision-making may also improve adherence [1]. Patients increasingly want to be informed by their doctors, and to be active in clinical decision-making $[3,4]$. In recent years, discrete choice experiments (DCEs) have been increasingly used to elicit patients' preferences for healthcare [5,6]. DCEs can quantify the relative importance of the various attributes that characterize a treatment and allow the trade-offs that respondents make between these to be quantified [7].

The aim of this study was to evaluate osteoporotic patients' preferences for medication attributes using a DCE, and to establish how patients make trade-offs between these attributes. This study differs from previously published DCEs in osteoporosis in several ways [8-10]. First, this study includes recently introduced routes and

\section{() Biomed Central}


timing of administration (for example, subcutaneous and intravenous injection) and the nature of potential sideeffects. Given potential differences in preferences between administration schemes, information on patients' preferences for these new administration schemes would be extremely useful for health professionals and decision-makers [11]. Second, this study expands the population studied to include men. Third, a rigorous qualitative research was performed to select medication attributes [12].

\section{Methods}

\section{Discrete choice experiment}

A DCE describes an intervention by its attributes (for example, effectiveness, side-effects, costs) and reports how patient's preference for an intervention are influenced by the type and levels of these attributes [7]. In the DCE, patients were asked to choose between two unlabelled drug treatments (A and B) and a no treatment (opt-out) option. The alternative treatments varied in several attributes, and patients were asked to select the treatment they would prefer. Patients were asked to make a series of such hypothetical choices. This research followed published DCEs guidelines [1,13] and used rigorous methods to select treatment attributes, to design the DCE and to conduct the statistical analysis.

\section{Attributes and levels}

The identification and selection of the DCE attributes is fundamental to obtaining valid results $[14,15]$. We conducted a nominal group technique to select the DCE attributes [14]. Full details on this are provided elsewhere [12]. In brief, patients' group discussions (four to eight participants per group, $n_{\text {total }}=26$ ) were conducted to prioritize a list of potentially important attributes of osteoporosis drug treatment. This list was developed from a literature review and discussions with experts. A ranking exercise and group discussions revealed five attributes that were consistently identified as important for patients: effectiveness, side-effects, mode and frequency of administration and out-of-pocket cost (Table 1) [12]. Levels were assigned to these attributes based on the current treatment using a literature review and discussion with experts $(n=5)$. For the side-effects of treatment, we focused on the types of common sideeffects [16].

\section{Experimental design}

It is not feasible to present an individual with all possible treatment combinations from the attributes and levels in Table 1. Experimental design techniques were used to draw a subset of treatment profiles to present to respondents in the DCE [5]. Specifically, a Bayesian efficient experimental design was used to select the subset using
Table 1 Attributes and levels for osteoporosis drug treatment

\begin{tabular}{lc}
\hline Efficacy in reducing the risk of future fractures & $20 \%$ \\
& $30 \%$ \\
& $40 \%$ \\
Possible side effects (affecting one in 50 patients) & $50 \%$ \\
& Gastrointestinal disorders \\
Flu-like symptoms \\
Skin reactions \\
Oral tablet \\
Mode of administration & Subcutaneous injection \\
Intravenous injection \\
Wreekly \\
Monthly \\
Every 3 months \\
Every 6 months \\
Yearly \\
$€ 5$ \\
$€ 15$ \\
Cost to you (per month)
\end{tabular}

Ngene software (version 1.1.1) [17] to select the subset. This experimental design maximizes the precision of estimated parameters (by maximizing the $D$ efficiency - a summary measure of the variance covariance matrix) for a given number of choice questions [18]. In this study, 15 choice sets were created. An example of a choice set is shown in Figure 1.

The construction of an efficient experimental design depends on patients' preferences, so we conducted a pilot DCE study $(n=10)$. We used the pilot results to obtain preliminary information about patients' preferences and then used this information to create the experimental design for the main study. The pilot DCE experimental design used a priori information about patients' preferences based on literature review [9] and discussions during the qualitative research (for example, higher effectiveness is preferred). We also wished to avoid presenting respondents with implausible treatment options (for example, a yearly oral tablet), and therefore we restricted the experimental design to include only realistic combinations between mode and frequency of administration that could appear in the design (that is, oral weekly or monthly tablets, subcutaneous injection every 3 or 6 months, and intravenous injection every 3 months or yearly). The experimental design based on pilot preference information suggested that 200 


\begin{tabular}{|c|c|c|}
\hline Question 1 & & \\
\hline & Treatment A & Treatment B \\
\hline $\begin{array}{l}\text { Efficacy (their effect) in reducing } \\
\text { the risk of future fractures }\end{array}$ & $30 \%$ & $40 \%$ \\
\hline $\begin{array}{l}\text { Possible side effects } \\
\text { (affecting } 1 \text { in } 50 \text { patients) }\end{array}$ & Flu-like symptoms & Skin reactions \\
\hline Mode of administration & Subcutaneous & Intravenous \\
\hline Frequency of administration & 3-month & Yearly \\
\hline Cost to you & $€ 15$ (per month) & $€ 25$ (per month) \\
\hline Which treatment would you choose? & Treatment A & Treatment B \\
\hline (Tick one box only) & & \\
\hline
\end{tabular}

Figure 1 Example of a choice set.

respondents would be sufficient power to detect the significance of most parameters.

\section{Questionnaire, data collection and patient recruitment}

In the questionnaire, patients received a thorough description of the DCE task. The attributes and levels were carefully explained and an example of a completed choice set was provided. One of the choice questions was asked twice to assess test-retest reliability. Each patient therefore received 16 choice sets. After completion of the choice tasks, respondents were asked how difficult they found the choice tasks on a seven-point scale. The DCE task is presented in Additional file 1. The questionnaire also asked questions on patients' characteristics. Individual 10-year probabilities of a hip fracture and a major osteoporotic fracture (FRAX score) [19] were calculated for each respondent by a doctor/researcher and added to the questionnaire afterwards.

The questionnaire was developed in English by a working group that included a patient and clinical and DCE experts, and was approved by two native English speakers, experts in osteoporosis. The questionnaire was then translated into French and Dutch by a medical translation company specializing in the translation of patient reported outcome measures (Pharma Quest Ltd, Oxford, United Kingdom) and the translation was checked and approved by two native French and Dutch speakers with medical backgrounds. The questionnaire was pilot tested with 15 patients (French-speaking $n=$ 10 , Dutch-speaking $n=5$ ) to check interpretation problems and face validity; no wording problems arose and only minor changes to layout were made.

Consecutive patients with, or at risk of, osteoporosis to whom medication (or lifestyle changes) was at least proposed were recruited during outpatients' clinics in two Belgian osteoporosis centers (Ghent and Liège). Explanation of the task and an example choice task was provided by the doctor or a researcher. The questionnaire was mainly completed by the patient at home and returned in a postage-paid envelope. Very few patients completed the questionnaire at the clinic but without any assistance from the doctor/researcher. Approval for this study was obtained from the ethics committee of Maastricht University Medical Center who coordinated this project and participants gave informed written consent.

\section{Statistical analyses}

From the DCE, we observe the respondent's choice of one treatment from the three alternatives presented in each choice set. Responses are analyzed based on random utility theory [20]. In this case, the utility that a patient $i$ assigns to a treatment $j, V_{i j}$, is modeled as the sum of two parts: a systematic part based on the attributes included in the DCE, and an error part $\varepsilon_{i j t}$. We specify $V_{i j}$ as:

$$
\begin{aligned}
V_{i j}= & \beta_{0}+\left(\beta_{1}+\eta_{1 \mathrm{i}}\right) \text { EFFICACY }_{\mathrm{j}}+\left(\beta_{2}+\eta_{2 \mathrm{i}}\right) \text { COST }_{\mathrm{j}} \\
& +\left(\beta_{3}+\eta_{3 \mathrm{i}}\right) \text { ORAL }_{1} \mathrm{M}_{\mathrm{j}}+\left(\beta_{4}+\eta_{4 \mathrm{i}}\right) \text { SUB }_{3} \mathrm{M}_{\mathrm{j}} \\
& +\left(\beta_{5}+\eta_{5 \mathrm{i}}\right) \text { SUB }_{6} \mathrm{M}_{\mathrm{j}}+\left(\beta_{6}+\eta_{6 \mathrm{i}}\right) \text { INT }_{3} \mathrm{M}_{\mathrm{j}} \\
& +\left(\beta_{7}+\eta_{7 \mathrm{i}}\right) \text { INT }_{1} \mathrm{Y}_{\mathrm{j}}+\left(\beta_{8}+\eta_{8 \mathrm{i}}\right) \text { FLUSYMPT }_{\mathrm{j}} \\
& +\left(\beta_{9}+\eta_{9 \mathrm{i}}\right) \text { SKINREACT }_{\mathrm{j}}+\varepsilon_{\mathrm{ij}}
\end{aligned}
$$

where $\beta_{0}$ is the constant reflecting the preferences for selecting treatment relative to no treatment, $\beta_{1}$ to $\beta_{9}$ are the mean attribute utility weights in the population, and $\eta_{1 \mathrm{i}}$ to $\eta_{9 \mathrm{i}}$ are error terms capturing individual-specific unexplained variation in the utility weights. Dummy coding was used (for ease of interpretation of the results) to describe all categorical variables $\left(\beta_{3}\right.$ to $\left.\beta_{9}\right)$. Reference levels for mode of administration and for side effects are weekly oral tablet and risk of gastrointestinal disorders, respectively. The sign of the coefficient reflects whether the attribute/level has a positive or a negative effect on treatment utility compared with the 
base level. The value of a coefficient indicates the relative importance of the attribute/level.

When developing a statistical model of respondents' choice it is important to account for respondents completing up to 15 choice tasks each and to allow preferences for treatment to vary across the sample. A mixed logit panel data model was therefore estimated using Nlogit, version 5 [21,22]. This model allows model parameters (preferences) to vary in the population. This variation is achieved by specifying a random parameter that has a distribution and estimating the mean $(\beta)$ and standard deviation of the error term $(\eta)$ to capture the parameter's distribution. If the standard deviation is significantly different from zero, this is interpreted as evidence of significant preference variation for the attribute in the sample.

Initially, we estimated models in which preferences for all attributes could vary in the population, and then in the final model - those attributes for which the estimated standard deviation was not significant (5\% level) - the preferences were specified to be the same in the population (fixed parameters). The random parameters for cost and efficacy were drawn from a log-normal distribution this allows us to constrain the parameter estimate to be either negative (for cost) or positive (for efficacy) [22]. All other random parameters were drawn from a normal distribution. The estimation was conducted using 2,000 Halton draws.

We also calculated marginal willingness to pay (WTP) and marginal willingness to trade efficacy (WTTE) of the attributes/levels. This allows us to compare preferences for all attributes measured with a common and interpretable metric either money or efficacy. A WTP (or WTTE) value represents how much one is willing to pay (or to trade) for a one-unit change in the attribute, and is calculating by taking the ratio of the mean parameter for the attribute/level to the mean parameter related to the cost (or efficacy). As the cost and efficacy variables were estimated as random parameters, the WTP and WTTE calculations must take this into account. As recommended in this case, the conditional constrained parameters were used [22].

The mixed logit model identifies attributes for which there is significant preference variation, but it does not explain why this variation exists. To understand the potential sources of preference variation, additional analyses included covariates (such as gender, age) in the model one by one. Significant covariates were then included together and nonsignificant covariates were excluded from this model. An adjusted pseudo- $R^{2}$ and finite Akaike information criterion were used to enable comparison of models with and without covariates. We also tested whether patients using a specific mode of administration had a stronger preference for this administration scheme by incorporating interactions between levels and covariates. Furthermore, to explore the impact of respondents who failed the test-retest, a sensitivity analysis was conducted by excluding these individuals. A subgroup analysis was also conducted in patients with high risk of fractures (defined as a FRAX major risk $>10 \%$ ) and in patients with low risk of fractures (defined as a FRAX major risk $\leq 10 \%$ ). To assess the significance of the differences between populations, a joint model was estimated using interaction terms.

\section{Results}

\section{Patients' characteristics}

A total of 301 questionnaires were distributed to patients; 268 were returned, representing a response rate of $89 \%$. Eleven questionnaires were excluded because the patient did not complete at least five choice sets in the DCE task. A total of 257 (85\%) questionnaires were included for data analysis. Respondents' sociodemographics and health characteristics are presented in Table 2 . There was no restriction on participation based on patients' race and ethnicity but patients were mainly Caucasian.

The difficulty of the task on a seven-point scale $(1=$ extremely easy to $7=$ extremely difficult) was estimated on average between 3 and 4 . The task was found to be extremely easy for 35 patients (13.6\%) while 19 patients (7.4\%) gave a score of 6 of 7. A total of 219 patients (85.2\%) chose the same alternative in the test-retest exercise. This is in line with existing test-retest results [15].

\section{Patients' preferences}

The distribution of choices across the choice sets is presented in Additional file 2. The main results of the mixed logit model are presented in Table 3. The estimated coefficients for efficacy and costs had the expected sign and were statistically significant. The positive sign of the efficacy parameter indicates that respondents prefer higher treatment efficacy, and the negative sign of the cost parameter indicates that respondents prefer paying less money for treatment. Patients prefer a 6-month subcutaneous injection and a monthly oral tablet compared with a weekly oral tablet (base level). There were no significant differences between weekly oral tablet, 3-monthly subcutaneous injection and yearly intravenous treatment; and no significant differences between 6-monthly subcutaneous injection and monthly oral tablet. Regardless of the administration mode, patients preferred a longer dosing regimen (monthly vs. weekly oral tablet; 6-monthly vs. 3monthly subcutaneous injection; yearly vs. 3-monthly intravenous treatment). The positive sign for the two sideeffect parameters indicates that patients disliked being at risk of gastrointestinal disorders (base) more than being at risk of skin reactions or flu-like symptoms.

The standard deviation parameters were statistically significant for all attributes except for the subcutaneous 


\section{Table 2 Patients' characteristics}

\begin{tabular}{|c|c|}
\hline Age (years, mean \pm standard deviation) & $67.1 \pm 10.4$ \\
\hline Female gender & $83.3 \%$ \\
\hline \multicolumn{2}{|l|}{ Educational level } \\
\hline Primary & $8.4 \%$ \\
\hline Some high school & $35.9 \%$ \\
\hline High school graduate & $30.3 \%$ \\
\hline College or university & $25.5 \%$ \\
\hline \multicolumn{2}{|l|}{ Size of household } \\
\hline One person & $29.9 \%$ \\
\hline Two people & $55.1 \%$ \\
\hline Three or more people & $15.0 \%$ \\
\hline \multicolumn{2}{|l|}{ Monthly household income } \\
\hline Up to $€ 999$ & $5.5 \%$ \\
\hline$€ 1,000$ to 1,499 & $33.1 \%$ \\
\hline$€ 1,500$ to 1,999 & $19.1 \%$ \\
\hline$€ 2,000$ to 2,499 & $17.8 \%$ \\
\hline$€ 2,500$ to 2,999 & $11.9 \%$ \\
\hline$€ 3,000+$ & $12.7 \%$ \\
\hline Diagnosis of osteoporosis & $89.8 \%$ \\
\hline Years since osteoporosis (mean \pm standard deviation) & $8.9 \pm 0.3$ \\
\hline With prior fracture(s) & $52.5 \%$ \\
\hline In the last year & $22.8 \%$ \\
\hline Patients on osteoporotic treatment & $69.8 \%$ \\
\hline \multicolumn{2}{|l|}{ Administration mode of current treatment } \\
\hline Oral & $72.2 \%$ \\
\hline Subcutaneous injection & $15.4 \%$ \\
\hline Intravenous injection & $12.4 \%$ \\
\hline \multicolumn{2}{|l|}{ Number of co-treatments } \\
\hline Zero or one & $19.3 \%$ \\
\hline Two or three & $40.6 \%$ \\
\hline Four or more & $40.2 \%$ \\
\hline $\begin{array}{l}\text { 10-year probability of a major osteoporotic fracture (FRAX) } \\
\text { (mean } \pm \text { standard deviation) }\end{array}$ & $14.3 \pm 7.5 \%$ \\
\hline $\begin{array}{l}\text { 10-year probability of a hip fracture (FRAX) } \\
\text { (mean } \pm \text { standard deviation) }\end{array}$ & $6.1 \pm 5.3 \%$ \\
\hline
\end{tabular}

injection, suggesting the presence of preference variation in the importance of the attribute/level across respondents. To gain more insight into how preferences vary, the distributions of the parameters or kernel density estimates of the individual parameter are presented in Additional file 3.

\section{Willingness to pay}

The WTP and WTTE for attributes/levels are presented in Table 4. For example, respondents were willing to pay a personal contribution of $€ 19.53$ more per month or to give up $13.52 \%$ of a drug's efficacy for the treatment mode of 6-month subcutaneous injection rather than a weekly oral tablet.

\section{High-risk patients versus low-risk patients}

The results of the model for high-risk and low-risk patients are presented in Table 5. Significant differences in preferences were found between these patient groups for the effectiveness and cost of treatment - the interactions between risk group and effectiveness and cost parameters were significant ( $5 \%$ level)). Lower effectiveness and higher costs are more acceptable for patients with highrisk of fractures. In addition, high-risk patients attached a higher (negative) value to being at risk for skin reactions than low-risk patients, and the constant (that is, preferences for drug treatment per se) was higher for high-risk patients. Preferences for drug administration did not differ significantly between patient groups.

\section{Additional analyses}

Excluding respondents who failed the test-retest $(n=$ 38) had no impact on the relative importance of the attributes (see Additional file 3). The inclusion of more covariates into the model did not significantly improve the adjusted McFadden's pseudo- $R^{2}$ but reduced the sample size by $17 \%$ due to missing values (see Additional file 3). We therefore did not include these covariates in the reference model. The only significant covariate effects we observed were that the preference for drug treatment was higher for men and patients with higher income (monthly household income $>€ 2,500$ per month). Other parameters were not affected by the inclusion of covariates. In addition, patients did not significantly prefer their current mode of administration over another mode of administration.

\section{Discussion}

This study suggests that patients with, or at risk of, osteoporosis have preferences for medications' attributes and are willing to trade between attributes when making treatment choices. Our results are consistent with $a$ priori expectations that patients prefer higher efficacy, lower costs and less frequent dosing regimens. In addition, patients preferred 6-month subcutaneous injection or monthly oral tablet over weekly oral tablet or intravenous injections, and they disliked being at risk for gastrointestinal disorders. Patients are willing to trade efficacy or to pay a personal contribution for better levels of other attributes. For most of the attributes, there was significant variation in patients' preferences.

Previous DCEs have investigated women's preference for osteoporosis drug treatment [8-10]. Our results confirm the findings of de Bekker-Grob and colleagues that patients prefer monthly oral tablet to weekly oral tablet [9] 
Table 3 Results from the panel mixed logit model

\begin{tabular}{|c|c|c|c|}
\hline Attributes and levels & Estimate ( $95 \%$ confidence interval) & $P$ value & Standard deviation \\
\hline Constant & $0.90^{* * *}(0.62$ to 1.17$)$ & 0.00 & - \\
\hline Efficacy ( $1 \%$ risk reduction) & $0.07^{* * *}(0.05 \text { to } 0.08)^{a}$ & 0.00 & $1.19^{* * *}(1.06$ to 1.30$)$ \\
\hline Cost per month $(€ 1)$ & $-0.05^{* * *}(-0.04 \text { to }-0.06)^{\mathrm{a}}$ & 0.00 & $1.24^{* * *}(1.09$ to 1.39$)$ \\
\hline \multicolumn{4}{|c|}{ Drug administration (reference level: weekly oral tablet) } \\
\hline Monthly oral tablet & $0.69^{* * *}(0.36$ to 1.03$)$ & 0.00 & $0.92^{* * *}(0.65$ to 1.19$)$ \\
\hline Subcutaneous injection 3-monthly & $0.16(-0.09$ to 0.42$)$ & 0.21 & $N S^{b}$ \\
\hline Subcutaneous injection 6-monthly & $0.75^{* * *}(0.44$ to 1.07$)$ & 0.00 & NS \\
\hline Intravenous injection 3-monthly & $-0.57^{* *}(-1.12$ to -0.01$)$ & 0.05 & $2.62^{* * *}(2.04$ to 3.20$)$ \\
\hline Intravenous injection yearly & $0.28(-0.12$ to 0.68$)$ & 0.17 & $1.56^{* * *}(1.17$ to 1.94$)$ \\
\hline \multicolumn{4}{|c|}{ Side-effects (reference level: gastrointestinal disorders) } \\
\hline Flu-like symptoms & $0.97^{* * *}(0.76$ to 1.18$)$ & 0.00 & $0.90^{* * *}$ (0.65 to 1.15$)$ \\
\hline Skin reactions & $0.63^{* * *}$ (0.41 to 0.85$)$ & 0.00 & $1.04^{* * *}(0.81$ to 1.26$)$ \\
\hline
\end{tabular}

Number of observations 3,822 ( 257 respondents $\times 15$ choices, minus 33 missing values).

Pseudo- $R^{2}=0.42$; log-likelihood $=-2,456.03$; Akaike information criterion $=1.29$.

${ }^{a}$ For the coefficients of efficacy and cost to you, $\exp (\beta)$ is shown. The standard deviation of the log-normal distribution is reported. ${ }^{b}$ Not significant and not included in the final model. ${ }^{* *} P<0.05$. ${ }^{* *} P<0.01$.

and those of Darba and colleagues suggesting no significant difference in preference between weekly oral regimen and yearly intravenous injection [8]. Fraenkel and colleagues also showed that preferences are strongly influenced by the route of administration but suggest a majority (65\%) of Americans preferred yearly intravenous infusion over weekly oral tablet [10]. Our study expands on the insights of these studies. We expand the population studied to include men, new recent administration routes and frequencies (for example, 6-month subcutaneous injection) and the nature of potential sideeffects. A rigorous qualitative research was also conducted to select attributes.
Results of this study could be very useful for health professionals and decision-makers, especially given the poor adherence to weekly oral regimens and the potential differences in healthcare costs associated with osteoporosis medications. Nonadherence to medication is a major problem among patients with osteoporosis and affects considerably the effectiveness and cost-effectiveness of drug therapy [23,24]. Determinants of poor adherence include inconvenient regimens [25]. In our study, many patients preferred a 6-monthly subcutaneous injection compared with weekly oral tablets and yearly intravenous injections. The recent introduction of 6-monthly subcutaneous injection of denosumab [26] and the recognition of

Table 4 Willingness to pay and willingness to trade efficacy for osteoporosis medication attributes ${ }^{\text {a }}$

\begin{tabular}{lcc}
\hline Attributes and levels & $\begin{array}{c}\text { Willingness to pay } \\
\text { (€ per month) }\end{array}$ & $\begin{array}{c}\text { Willingness to trade efficacy } \\
\text { (\% risk reduction) }\end{array}$ \\
\hline Efficacy (1\% risk reduction) & $3.73(3.01$ to 4.44$)$ & - \\
Cost (€1) & - & $-2.27(-1.58$ to -2.96$)$ \\
Drug administration (reference level: weekly oral tablet) & $16.16(12.85$ to 19.47$)$ & $-10.16(-7.88$ to -12.50$)$ \\
$\quad$ Monthly oral tablet & $4.24(3.72$ to 4.76$)$ & $-2.93(-2.57$ to -3.30$)$ \\
$\quad$ Subcutaneous injection 3-monthly & $19.53(17.15$ to 21.92$)$ & $-13.52(-11.82$ to -15.22$)$ \\
Subcutaneous injection 6-monthly & $-15.28(-23.23$ to -7.34$)$ & $-5.66(14.31$ to 3.01$)$ \\
Intravenous injection 3-monthly & $11.75(5.64$ to 17.85$)$ & -1.88 to -9.77$)$ \\
Intravenous injection yearly & & $-9.48(-7.13$ to -11.83$)$ \\
Side-effects (reference level: gastrointestinal disorders) & $25.21(13.06$ to 20.50$)$ & 14.20 to -19.16$)$ \\
Flu-like symptoms & $16.78(13.06$ to 20.50$)$ & \\
Skin reactions & &
\end{tabular}

Data presented as mean (95\% confidence interval). A positive willingness to pay means that patients are willing to pay a personal contribution for the attribute/level, while a negative willingness to trade efficacy means that patients are willing to give up treatment efficacy for the attribute/level. ${ }^{\mathrm{a}}$ Using the conditional constrained distribution. 
Table 5 Differences between high-risk and low-risk patients' preferences for osteoporosis drug treatment

\begin{tabular}{|c|c|c|c|}
\hline Attributes and levels & $\begin{array}{l}\text { High risk patients } \\
\text { (FRAX major }>10 \% \text { ) }\end{array}$ & $\begin{array}{l}\text { Low-risk patients } \\
\text { (FRAX major } \leq 10 \% \text { ) }\end{array}$ & $P$ value $^{\mathrm{a}}$ \\
\hline Number of patients & 139 & 114 & \\
\hline Pseudo- $R^{2}$ & 0.39 & 0.42 & \\
\hline Log-likelihood & $-1,378.35$ & $-1,085.55$ & \\
\hline Constant & $1.50^{* * *}(1.17$ to 1.83$)$ & $-0.05(-0.52$ to 0.43$)$ & 0.01 \\
\hline \multirow[t]{2}{*}{ Efficacy ( $1 \%$ risk reduction) } & $0.04 * * *(0.03$ to 0.04$)$ & $0.14^{* * *}(0.11$ to 0.17$)$ & 0.00 \\
\hline & SD: $1.65^{* * *}$ & SD: $1.01^{* * *}$ & \\
\hline \multirow[t]{2}{*}{ Cost per month $(€ 1)$} & $-0.02^{* * *}(-0.02$ to -0.03$)$ & $-0.08^{* * *}(-0.06$ to -0.09$)$ & 0.00 \\
\hline & SD: $1.45^{* * *}$ & SD: $0.67^{* * *}$ & \\
\hline \multicolumn{4}{|c|}{ Drug administration (reference level: weekly oral tablet) } \\
\hline \multirow[t]{2}{*}{ Monthly oral tablet } & $0.57^{* *}(0.08$ to 1.06$)$ & $1.14^{* * *}(0.47$ to 1.82$)$ & 0.14 \\
\hline & SD: $0.94^{* * *}$ & SD: $1.87^{* * *}$ & \\
\hline \multirow[t]{2}{*}{ Subcutaneous injection 3-monthly } & $0.14(-0.19$ to 0.47$)$ & $0.28(-0.17$ to 0.74$)$ & 0.14 \\
\hline & SD: NS & SD: NS & \\
\hline \multirow[t]{2}{*}{ Subcutaneous injection 6-monthly } & $0.57^{* * *}(0.17$ to 0.96$)$ & $1.55^{* * *}$ (0.97 to 2.14$)$ & 0.06 \\
\hline & SD: NS & SD: NS & \\
\hline \multirow[t]{2}{*}{ Intravenous injection 3-monthly } & $-0.28(-0.88$ to 0.31$)$ & $-0.24(-1.39$ to 0.91$)$ & 0.25 \\
\hline & SD: $1.82^{* * *}$ & SD: $4.84^{* * *}$ & \\
\hline \multirow[t]{2}{*}{ Intravenous injection yearly } & $0.28(-0.13$ to 0.69$)$ & $0.75^{* *}(0.05$ to 1.45$)$ & 0.33 \\
\hline & SD: $0.81^{* * *}$ & SD: $2.15^{* * *}$ & \\
\hline \multicolumn{4}{|c|}{ Side effects (reference level: gastrointestinal disorders) } \\
\hline \multirow[t]{2}{*}{ Flu-like symptoms } & $0.66^{* * *}$ (0.36 to 0.95$)$ & $1.51^{* * *}(1.07$ to 1.95$)$ & 0.57 \\
\hline & SD: $0.91^{* * *}$ & SD: $1.18^{* * *}$ & \\
\hline \multirow[t]{2}{*}{ Skin reactions } & $0.45^{* *}(0.05$ to 0.85$)$ & $0.49^{* *}(0.10$ to 0.87$)$ & 0.05 \\
\hline & SD: $1.31^{* * *}$ & SD: $1.04^{* * *}$ & \\
\hline
\end{tabular}

Data presented as estimate (95\% confidence interval). SD, standard deviation; NS, not significant. ${ }^{a} P$ value was estimated in a joint model with interaction terms. ${ }^{* *} P<0.05$. ${ }^{* * *} P<0.01$.

the importance of patients' preferences could therefore potentially improve patient satisfaction and adherence with therapy [27]. Our results could also inform healthcare decision-making, in particular for drug reimbursement, where insights into the preferences of patients groups should be taken into account alongside medical and economic considerations [28].

In addition, the variation in the patients' preferences for attribute levels observed in our study highlights the importance to take into account individual preferences into clinical decision-making to improve osteoporosis care. Relying solely on sample average preferences will probably be insufficient to optimize medical doctors' sensitivity to the preferences of an individual and unique patient during a consultation. Informing individual patients about alternative options and their outcomes, and involving them in decision-making, would be very important to improve patient satisfaction and the outcome of medical care [29].
Our study has some potential limitations. First, although consecutive patients were invited to participate in this study, we cannot exclude selection bias as some patients did not want, or were not able, to fill in the questionnaire. Second, generalizability and transferability of our findings may be limited by recruiting patients from two osteoporosis centers in one country only. A cross-country comparison is ongoing in seven European countries. Preferences for attributes/levels may differ according to a number of factors including age, income, education or prior fractures [30]. While we do not find evidence of preference variation associated with these factors in our study, the cross-country comparison will investigate this further. Third, we focused on the nature of common side-effects, not on their frequency and rare complications. Rare adverse events will be as (in)frequent in all categories of anti-resorptive drugs. Therefore, adding osteonecrosis of the jaw and atypical femoral fracture to the side-effect attribute would 
probably not differentiate between patient preferences across existing drugs. Attributes were selected using a rigorous qualitative method as recommended in good practice guidelines $[1,13]$. Finally, one could point out that the individual 10-year probability of fractures was not provided to the patients before completing the questionnaire. Only 35 (14\%) patients reported knowing their FRAX score.

\section{Conclusions}

This study revealed that osteoporotic patients prefer 6monthly subcutaneous injection and oral monthly tablets, and disliked gastrointestinal disorders. Moreover, they were willing to trade efficacy or to pay a personal contribution for their preferred outcomes. We found differences in preferences across patients, which highlights the importance of clinical decision-making taking individual preferences into account to improve osteoporosis care.

\section{Additional files}

Additional file 1: The questionnaire given to the patients.

Additional file 2: A table presenting the distribution of choices (treatment $A$, treatment $B$, no treatment) across the 15 choice sets. Additional file 3: Shows tables and figures presenting additional results including estimates of models with excluding respondents who failed the test-retest or with inclusion of covariates, and kernel density estimates of the individual parameters.

\section{Abbreviations}

DCE: discrete choice experiment; WTP: willingness to pay; WTTE: willingness to trade efficacy.

\section{Competing interests}

$\mathrm{MH}$ has received research grants and/or lecture fees from Amgen, Novartis, Pfizer, Servier and SMB. SG has received speakers fees and/or research support from Amgen, Daiichi-Sankyo, Eli Lilly, Glaxo SmithKline, Merck Sharp \& Dohme, Novartis, Nycomed, Warner-Chillcott, Sanofi-Aventis, Servier, and Roche. J-YR received consulting fees, paid advisory boards, lecture fees, and/or grant support from Servier, Novartis, Negma, Lilly, Wyeth, Amgen, GlaxoSmithKline, Roche, Merckle, Nycomed, NPS, Theramex, UCB, Merck Sharp and Dohme, Rottapharm, IBSA, Genevrier, Teijin, Teva, Ebewee Pharma, Zodiac, Analis, Novo-Nordisk, and Bristol Myers Squibb. The remaining authors state that they have no competing interests.

\section{Authors' contributions}

$M H, A B, B G D, C D D, T v d W$ and $W W$ were responsible for design of the study. SG and J-YR were responsible for data collection. MH, AB, BGD, CDD and WW were responsible for data analysis. $\mathrm{MH}$ had full access to the data and takes responsibility for the integrity of the data and the accuracy of the data analysis. $\mathrm{MH}$ drafted the manuscript and all other authors revised it critically for important intellectual content. All authors approved the final version.

\section{Acknowledgements}

Financial support for this study was provided by Amgen (Zug, Switzerland). The funding agreement ensured the authors' independence in designing the study, interpreting the data, and writing and publishing the report. An ESCEO-Amgen Osteoporosis Fellowship grant received at the World Congress on Osteoporosis (IOF WCO-ECCEO10, Florence 2010) was also used to collect data in Belgium.

The authors would like to thank Jolien Delahaye, Jean-Marc Kaufman, Joke Poppe and Véronique van den Bossche (Ghent University Hospital) and Rita
Deroisy, Sandra Lambrechts and Lorenzo Leonori (University of Liege) for helping in data collection; Ed Porquie, our patient partner; Wafa Ben Sedrine for data entry; John Rose for help in experimental design; and all of the patients for their participation. Finally, the authors would also thank two reviewers for critical review and helpful comments on the manuscript.

\section{Author details}

${ }^{1}$ Department of Health Services Research, School for Public Health and Primary Care (CAPHRI), Maastricht University, P.O. Box 616, 6200 MD Maastricht, the Netherlands. ${ }^{2}$ Department of Business Economics, Erasmus Rotterdam University, Rotterdam, the Netherlands. ${ }^{3}$ Department of Clinical Epidemiology and Medical Technology Assessment, CAPHRI, Maastricht University, Maastricht, the Netherlands. ${ }^{4}$ Department of Family Medicine, CAPHRI, Maastricht University, Maastricht, the Netherlands. ${ }^{5}$ Department of Rheumatology and Endocrinology, Ghent University Hospital, Gent, Belgium. ${ }^{6}$ Department of Public Health, Epidemiology and Health Economics, University of Liege, Liege, Belgium. ${ }^{7}$ Health Economics Research Unit, Institute of Applied Health Sciences, University of Aberdeen, Aberdeen, UK. ${ }^{8}$ Department of Internal Medicine, CAPHRI, Maastricht University, Maastricht, the Netherlands.

Received: 13 July 2013 Accepted: 10 January 2014

Published: 31 January 2014

\section{References}

1. Bridges JF, Hauber AB, Marshall D, Lloyd A, Prosser LA, Regier DA, Johnson FR, Mauskopf J: Conjoint analysis applications in health - a checklist: a report of the ISPOR Good Research Practices for Conjoint Analysis Task Force. Value Health 2011, 14:403-413.

2. Brennan PF, Strombom I: Improving health care by understanding patient preferences: the role of computer technology. JAMIA 1998, 5:257-262.

3. Salzburg Global Seminar: Salzburg statement on shared decision making BMJ 2011, 342:d1745.

4. Murphy DR, Smolen $\sqcup$, Klein TM, Klein RW: The cost effectiveness of teriparatide as a first-line treatment for glucocorticoid-induced and postmenopausal osteoporosis patients in Sweden. BMC Musculoskelet Disord 2012, 13:213.

5. de Bekker-Grob EW, Ryan M, Gerard K: Discrete choice experiments in health economics: a review of the literature. Health Econ 2012, 21:145-172.

6. Marshall D, Bridges JF, Hauber B, Cameron R, Donnalley L, Fyie K, Johnson FR: Conjoint analysis applications in health - how are studies being designed and reported? An update on current practice in the published literature between 2005 and 2008. Patient 2010, 3:249-256.

7. Ryan M: Discrete choice experiments in health care. BMJ 2004, 328:360-361.

8. Darba J, Restovic G, Kaskens L, Balbona MA, Carbonell A, Cavero P, Jordana M, Prieto C, Molina A, Padró I: Patient preferences for osteoporosis in Spain: a discrete choice experiment. Osteoporos Int 2011, 22:1947-1954.

9. de Bekker-Grob EW, Essink-Bot ML, Meerding WJ, Pols HA, Koes BW, Steyerberg EW: Patients' preferences for osteoporosis drug treatment: a discrete choice experiment. Osteoporos Int 2008, 19:1029-1037.

10. Fraenkel L, Gulanski B, Wittink D: Patient treatment preferences for osteoporosis. Arthritis Rheum 2006, 55:729-735.

11. Cramer JA, Gold DT, Silverman SL, Lewiecki EM: A systematic review of persistence and compliance with bisphosphonates for osteoporosis. Osteoporos Int 2007, 18:1023-1031.

12. Hiligsmann $M$, van Durme $C$, Geusens $P$, Dellaert BG, Dirksen CD, van der Weijden T, Reginster JY, Boonen A: Nominal group technique to select attributes for discrete choice experiments: an example for drug treatment choice in osteoporosis. Patient Prefer Adherence 2013, 7:133-139.

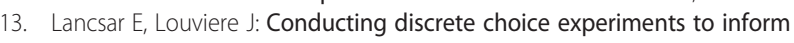
healthcare decision making: a user's guide. Pharmacoeconomics 2008, 26:661-677.

14. Coast J, Al-Janabi H, Sutton EJ, Horrocks SA, Vosper AJ, Swancutt DR, Flynn $\mathrm{TN}$ : Using qualitative methods for attribute development for discrete choice experiments: issues and recommendations. Health Econ 2012, 21:730-741.

15. Ryan M, Gerard K, Amaya-Amaya M: Using Discrete Choice Experiments to Value Health and Health Care. Dordrecht: Springer; 2008 
16. Rizzoli R, Reginster JY, Boonen S, Bréart G, Diez-Perez A, Felsenberg D, Kaufman JM, Kanis JA, Cooper C: Adverse reactions and drug-drug interactions in the management of women with postmenopausal osteoporosis. Calcif Tissue Int 2011, 89:91-104.

17. Ngene. [http://www.choice-metrics.com/]

18. Reed Johnson F, Lancsar E, Marshall D, Kilambi V, Mühlbacher A, Regier DA, Bresnahan BW, Kanninen B, Bridges JF: Constructing experimental designs for discrete-choice experiments: report of the ISPOR conjoint analysis experimental design good research practices task force. Value Health 2013, 16:3-13.

19. FRAX. [www.shef.ac.uk/FRAX]

20. Kristoffersen DT, Helgeland J, Clench-Aas J, Laake P, Veierod MB: Comparing hospital mortality - how to count does matter for patients hospitalized for acute myocardial infarction (AMI), stroke and hip fracture. BMC Health Serv Res 2012, 12:364.

21. https://www.limdep.com/products/nlogit/.

22. Hensher D, Rose J, Greene W: Applied Choice Analysis: A Primer. Cambridge, UK: Cambridge University Press; 2007.

23. Siris ES, Selby PL, Saag KG, Borgstrom F, Herings RM, Silverman SL: Impact of osteoporosis treatment adherence on fracture rates in North America and Europe. Am J Med 2009, 122:S3-S13.

24. Hiligsmann M, McGowan B, Bennett K, Barry M, Reginster JY: The clinical and economic burden of poor adherence and persistence with osteoporosis medications in Ireland. Value Health 2012, 15:604-612.

25. Rossini M, Bianchi G, Di Munno O, Giannini S, Minisola S, Sinigaglia L, Adami S: Treatment of Osteoporosis in clinical Practice (TOP) Study Group. Osteoporos Int 2006, 17:914-921.

26. Cummings SR, San Martin J, McClung MR, Siris ES, Eastell R, Reid IR, Delmas P, Zoog HB, Austin M, Wang A, Kutilek S, Adami S, Zanchetta J, Libanati C, Siddhanti S, Christiansen C: Denosumab for prevention of fractures in postmenopausal women with osteoporosis. N Engl J Med 2009, 361:756-765.

27. Mulley AG, Trimble C, Elwyn G: Stop the silent misdiagnosis: patients' preferences matter. BMJ 2012, 345:e6572.

28. Hiligsmann M, Kanis JA, Compston J, Cooper C, Flamion B, Bergmann P, Body JJ, Boonen S, Bruyere O, Devogelaer JP, Goemaere S, Kaufman JM, Rozenberg S, Reginster JY: Health technology assessment in osteoporosis. Calcif Tissue Int 2013, 93:1-14

29. Montori VM, Shah ND, Pencille LJ, Branda ME, Van Houten HK, Swiglo BA, Kesman RL, Tulledge-Scheitel SM, Jaeger TM, Johnson RE, Bartel GA, Melton $\sqcup$ 3rd, Wermers RA: Use of a decision aid to improve treatment decisions in osteoporosis: the osteoporosis choice randomized trial. Am J Med 2011, 124:549-556.

30. Silverman S, Calderon A, Kaw K, Childers TB, Stafford BA, Brynildsen W, Focil A, Koenig M, Gold DT: Patient weighting of osteoporosis medication attributes across racial and ethnic groups: a study of osteoporosis medication preferences using conjoint analysis. Osteoporos Int 2013, 7:2067-2077.

doi:10.1186/ar4465

Cite this article as: Hiligsmann et al.: Patients' preferences for osteoporosis drug treatment: a discrete-choice experiment. Arthritis Research \& Therapy 2014 16:R36.

\section{Submit your next manuscript to BioMed Central and take full advantage of:}

- Convenient online submission

- Thorough peer review

- No space constraints or color figure charges

- Immediate publication on acceptance

- Inclusion in PubMed, CAS, Scopus and Google Scholar

- Research which is freely available for redistribution

Submit your manuscript at www.biomedcentral.com/submit 